Original article

\title{
Prevalence and appropriateness of drug prescriptions for peptic ulcer and gastro-esophageal reflux disease in a cohort of hospitalized elderly
}

\author{
L. Pasina ${ }^{\text {a, } *}$, A. Nobili ${ }^{\text {a }}$, M. Tettamanti ${ }^{\text {a }}$, F. Salerno ${ }^{\text {b }}$, S. Corrao ${ }^{c}$, A. Marengoni ${ }^{\text {d }}$, A. Iorio ${ }^{\text {, }}$ \\ M. Marcucci ${ }^{\text {e }}$, P.M. Mannucci ${ }^{\mathrm{f}}$ \\ and on behalf of REPOSI Investigators ${ }^{1}$
}

\footnotetext{
${ }^{a}$ Mario Negri Institute for Pharmacological Research, Milan, Italy

b Internal Medicine I, Policlinico IRCCS San Donato, University of Milan, Italy

c Dipartimento Biomedico di Medicina Interna e Specialistica, University of Palermo, Italy

d Geriatric Unit, Spedali Civili, Department of Medical and Surgery Sciences, University of Brescia, Italy

e Department of Internal Medicine, University of Perugia, Italy

f Scientific Direction, IRCCS Maggiore Hospital Foundation, Milan, Italy
}

\section{A R T I C L E I N F O}

\section{Article history:}

Received 7 September 2010

Received in revised form 23 November 2010

Accepted 23 November 2010

Available online 21 December 2010

\section{Keywords:}

Proton pump inhibitors

Appropriateness

Elderly

\begin{abstract}
A B S T R A C T
Background: Proton pump inhibitors (PPI) are among the most commonly prescribed medicines and their overuse is widespread in both primary and secondary care. Inappropriate prescription is of particular concern among elderly patients, who have often multiple comorbidities and need many drugs.

Methods: We evaluate the appropriateness of drugs for peptic ulcer or gastro-esophageal reflux disease (GERD) in a sample of elderly patients (65 years old or older) at admission and discharge in 38 internal medicine wards between January 2008 and December 2008, according to the presence of specific conditions or gastro-toxic drug combinations.

Results: Among 1155 patients eligible for the analysis, 466 (40.3\%) were treated with drugs for GERD or peptic ulcer were at hospital admission and 647 (56.0\%) at discharge; $62.4 \%$ of patients receiving a drug for peptic ulcer or GERD at admission and 63.2\% at discharge were inappropriately treated. Among these, the number of other drugs prescribed was associated with greater use of drugs for peptic ulcer or GERD, even after adjustment for age, sex and number of diagnoses at admission (OR 95\% CI =1.26 (1.18-1.34), $p=.0001)$ or discharge (OR 95\% $\mathrm{CI}=1.11(1.05-1.18), p=0.0003)$.

Conclusions: Prevalence of inappropriate prescription of drugs for peptic ulcer or GERD remained almost the same at admission and discharge. Inappropriate use of these drugs is related to the concomitant use of other drugs. Careful assessment of clinical conditions and stricter adherence to evidence-based guidelines are essential for a rational and cost-effective use of drugs for peptic ulcer or GERD.
\end{abstract}

(c) 2010 European Federation of Internal Medicine. Published by Elsevier B.V. All rights reserved.

\section{Background}

Drugs for peptic ulcer or gastro-esophageal reflux disease (GERD), especially proton pump inhibitors (PPI), are among the most commonly prescribed medicines. PPI overuse is widespread in both primary and secondary care with great implications on drug costs in the industrialized world [1]; in Italy it accounts for about $7 \%$ of gross pharmaceutical expenditure [2]. PPI certainly offer an improvement in

\footnotetext{
* Corresponding author. Laboratory for Quality Assessment of Geriatric Therapies and Services, Drug Information Service for the Elderly, Istituto di Ricerche Farmacologiche "Mario Negri", Via Giuseppe La Masa, 19, 20156 Milano, Italy. Tel.: +39 02 39014 579; fax: +390239001916.

E-mail address: luca.pasina@marionegri.it (L. Pasina).

1 REPOSI denotes Registry of Polytherapies SIMI (Società Italiana di Medicina Interna).
}

the treatment of common and important gastrointestinal diseases. They are effective in the cure or prevention of peptic acid disorders and in the management of GERD, esophagitis, gastric ulcer, bleeding peptic ulcer, eradication of Helicobacter pylori, dyspepsia, ZollingerEllison syndrome and prevention of gastrointestinal (GI) toxicity induced by non-steroidal anti-inflammatory drugs (NSAID).

However, some studies have suggested that between $25 \%$ and $81 \%$ of patients taking PPI had no appropriate indication and in many cases physicians fail to provide specific instructions about how long to continue treatment [3-11]. PPI are frequently used in patients who do not meet the criteria for appropriate use or for non-evidence-based indications where less powerful, cheaper agents would be effective for the treatment of symptoms. Although there is evidence about superiority of the PPI over $\mathrm{H}_{2}$ receptor antagonists and others drugs for the treatment of GERD or peptic ulcer, thanks to their stronger and longer action, other drugs could often be an effective and safe alternative for many patients [12-14]. 
Inappropriate prescriptions are of particular concern among elderly patients, who normally have multiple comorbidities, take many drugs and are at higher risk of adverse drug reactions [15-17]. Although generally well tolerated, PPI can cause serious adverse reactions. Their short-term use has been associated with infections such as community-acquired pneumonia [18-21] or Clostridium difficile diarrhea $[22,24]$ due to low gastric acidity, and with a loss of efficacy of clopidogrel as a result of drug interaction [25-30]. Longterm use has been related to increases in hip fractures [31-33], delayed diagnosis of gastric cancer and increased risk of all-cause mortality [34,35].

The aims of the present analysis, in the cohort of elderly patients enrolled in the REPOSI study, were to evaluate the rate of prescriptions of drugs for peptic ulcer or GERD at admission and discharge in a sample of Italian internal medicine wards and to analyze the appropriateness of use in relation to evidence-based indications.

\section{Methods}

\subsection{Data collection}

The Registro Politerapie SIMI (REPOSI) study is a collaborative, independent, voluntary effort by the Italian Society of Internal Medicine (SIMI) and the Mario Negri Institute for Pharmacological Research, run between January 2008 and December 2008 in a sample of 38 internal medicine wards in various Italian regions. This multicenter collaborative longitudinal study was designed to create a network of internal medicine and geriatric wards in order to collect information on a sample of elderly in-patients with multiple diseases, needing polytherapy, to describe the prevalence of these diseases and the treatments, to analyze the predictors, and to record the main clinical outcomes at hospital discharge.

To ensure an unselected population of elderly patients admitted to internal medicine wards, during four-week period three months apart (one in February, one in June, one in September, and one in December 2008) the first ten patients admitted to the wards participating in the study were consecutively recruited if they were 65 years old or older. For this observational study, conducted on anonymous patient records, approval by the Ethics Committee was not required. Participation in the study was voluntary and all the patients gave signed informed consent. For each patient, a standardized web-based case report form was completed by the attending physician, including socio-demographic factors, clinical parameters, diagnoses and treatments at hospital admission and discharge, clinical events while in hospital, and outcome. All the data were collected and checked by a central monitor at the Mario Negri Institute for Pharmacological Research, Milan.

\subsection{Diseases and drug appropriateness}

Diagnoses examined were recorded at hospital admission and discharge and confirmed by caregivers on the basis of clinical examination, anamnesis, laboratory and instrumental data. Diagnoses were made using standardized criteria. The International Classification of Diseases-Ninth Revision (ICD-9) (World Health Organization, 1987) [36] was used for classifying all diseases. Drugs were recorded according to the Anatomical Therapeutic Chemical classification system (ATC) (WHO 1990) [37].

The appropriateness of drug prescriptions for peptic ulcer and GERD (ATC classification code: A02B) was assessed retrospectively taking into account the presence of a pathological condition requiring their use or the presence of gastro-toxic drug combinations [6,38,39], which we defined as concomitant therapy with NSAIDs or low doses of acetylsalicylic acid (ASA) together with oral corticosteroids or antithrombotic therapy. Criteria used to identify gastro-toxic drug combinations are in accordance with the stronger evidence-based indications [6], which reflect the rules [7] of the Agenzia Italiana del Farmaco (AIFA, the Italian Drug Agency) for gastroprotection with PPIs and misoprostol in order to prevent gastrointestinal toxicity in patients using gastro-toxic drug combinations (Box 1).

The pathological conditions in which we assessed the appropriateness of A02B drug use were classified on the basis of the diagnosis at hospital admission and/or at discharge, with the specific ICD-9 codes. We considered all patients with diseases of the esophagus, stomach, and duodenum (ICD-9 codes from 530 to 538 and 578), or with $H$. pylori infection (ICD-9 code 041.86).

Drugs for peptic ulcer or GERD were identified from the list of drugs administered at admission and discharge according to the ATC classification (the third level code A02B). Similarly, gastro-toxic drug combinations were identified according to the second, third, fourth or fifth level of the ATC code as follows: H02 for corticosteroids, M01A and N02BA for non-steroidal anti-inflammatory drugs, B01A, B01AB, and B01AC for oral antithrombotic drugs other than ASA, and B01AC06 and for ASA. M01B were not included in analysis because no drug is available in Italy with this code. All N02BA drugs recorded at hospital admission corresponded to acetylsalicylic acid $100 \mathrm{mg}$ prescribed for cardioprotection on the basis of clinical indication recorded. So these medication were coded as B01AC06. In accordance with this criteria, patients appropriately treated with drug for peptic ulcer and GERD were those with gastrointestinal diseases, such as ulcer, esophageal diseases, gastritis, duodenitis or Helicobacter infection or those receiving a gastro-toxic drug combinations, such as concomitant therapy with NSAIDs or low doses of acetylsalicylic acid (ASA), together with oral corticosteroids or antithrombotic therapy.

\section{Statistical analysis}

Confidence intervals on percentages of drug use were computed using score confidence intervals.

Statistical significance of differences in possible predictors for inappropriate prescription of drugs for the treatment of GERD or peptic ulcer was evaluated using logistic regression, at the univariate and multivariate levels. Analyses were done with JMP, v. 8.0.2 (SAS Institute Inc.). Multivariate analyses were corrected for age, sex, number of drugs and number of diagnoses.

\section{Results}

In all 38 departments of internal medicine and geriatric wards participated in the REPOSI study and recruited 1332 patients; 111 were excluded because of lack of discharge information (they were transferred to another hospital ward not participating in the study) and 66 because they died inhospital. Therefore 1155 patients were eligible for this analysis.

Drugs for GERD or peptic ulcer were given to 466 patients (40.3\%) at admission and 647 (56.0\%) at discharge. The mean number of drugs used and diagnoses made were higher in patients given drugs for peptic ulcer or GERD than in untreated patients (Table 1). PPI were the

\section{Box 1}

Rules of AIFA for gastroprotection with PPIs and misoprostol

Rules of the AIFA allow the prescription of PPIs or misoprostol for gastroprotection in the case that a patient chronically treated with NSAIDs or ASA has concomitantly the presence of history or active peptic ulcer; or concomitant therapy with an anticoagulant agents or corticosteroids; or advanced age (not specified if older than 65 or 75). Rules underline that advanced age or anticoagulant therapy is not a criteria to treat all elderly with gastropotector, but must be considered a factor suggestive of populations at increased risk and not a recommendation. 
Table 1

Main characteristics of patients recruited for the analyses.

\begin{tabular}{llllll}
\hline & \multicolumn{2}{l}{$\begin{array}{l}\text { At admission } \\
(n=1155)\end{array}$} & & \multicolumn{2}{l}{$\begin{array}{l}\text { At discharge } \\
(n=1155)\end{array}$} \\
\cline { 2 - 3 } \cline { 5 - 6 } \cline { 5 - 6 } & $\begin{array}{l}\text { Treated } \\
\text { with A02B }\end{array}$ & $\begin{array}{l}\text { Not treated } \\
\text { with A02B }\end{array}$ & $\begin{array}{l}\text { Treated } \\
\text { with A02B }\end{array}$ & $\begin{array}{l}\text { Not treated } \\
\text { with A02B }\end{array}$ \\
\hline Total & 466 & 689 & & 647 & 508 \\
Patients with disease or & $175(37.6)$ & $59(8.6)$ & & $238(36.8)$ & $41(8.1)$ \\
$\quad$ gastro-toxic & & & & & \\
$\quad$ combinations (\%) & & & & & \\
Age, years (mean $\pm S D)$ & $79.2 \pm 7.7$ & $79.2 \pm 7.5$ & & $79.1 \pm 7.7$ & $79.3 \pm 7.4$ \\
Women (\%) & 55.2 & 52.7 & & 53.0 & 54.5 \\
Drugs, no (mean $\pm S D)^{\mathrm{b}}$ & $5.4 \pm 2.7$ & $3.9 \pm 2.4$ & & $5.8 \pm 2.9$ & $4.9 \pm 2.4$ \\
Diagnoses, No (mean $\pm \mathrm{SD})$ & $4.9 \pm 2.4$ & $3.8 \pm 2.2$ & & $6.3 \pm 2.5$ & $5.5 \pm 2.4$ \\
\hline
\end{tabular}

a Drugs for peptic ulcer or gastro-esophageal reflux disease.

b Excluding the drugs for peptic ulcer or GERD.

most frequently prescribed drugs for these indications, accounting for about $95.3 \%$ of prescriptions at admission and $95.5 \%$ at discharge. Lansoprazole and omeprazole were the main active principles prescribed (Table 2).

At admission 291 patients (62.4\% of those receiving a drug for peptic ulcer or GERD) and 409 at discharge (63.2\%) were treated even though they had no specific pathology or gastro-toxic drug combinations that could justify the use of these drugs. Furthermore, 227 patients (78.0\%; 95\% CI, 72.9\%-82.4\%) received a drug for peptic ulcer or GERD inappropriately at both admission and discharge. Only in 36 cases (12.4\%; 95\% CI, 9.1\%-16.7\%) were these drugs appropriately withdrawn at hospital discharge. At admission 59 patients (5.1\%; 95\% $\mathrm{CI}, 4.0 \%-6.5 \%)$ with gastrointestinal diseases or receiving a gastrotoxic drug combinations and 41 (3.6\%;95\% CI, 2.6\%-4.8\%) at discharge were inappropriately not treated with a drug for peptic ulcer or GERD. Among patients inappropriately not treated ad admission 27 (48.5\%; 95\% CI, 33.7\%-58.3\%) received the treatment at discharge. Sex and mean age were not different for patients who received these drugs appropriately or inappropriately at either admission or discharge. The mean numbers of drugs prescribed were higher among patients with inappropriate prescription at admission $(5.4 \pm 2.7$ and $5.1 \pm 2.8)$ and discharge $(5.7 \pm 2.8$ and $5.4 \pm 2.8)$. However the mean number of diagnoses was higher in patients treated appropriately than inappropriately at admission $(4.9 \pm 2.2$ and $4.3 \pm 2.3)$ and discharge $(6.2 \pm 2.4$ and $5.9 \pm 2.4)$. In addition, among patients appropriately not treated at admission with a drug for peptic ulcer or GERD, the drug was prescribed at discharge to 149 (23.3\%, 95\% CI, 20.2\%-26.7\%), although it did not need to be continued.

Among appropriately treated patients the main gastrointestinal diseases associated with prescriptions at hospital admission or discharge are reported in Table 3. Gastro-toxic drug combinations were the second cause of prescription. Low doses of ASA with another antithrombotic drug was the combination most frequently prescribed

Table 2

Number of patients treated with active principles for peptic ulcer or GERD at admission and discharge.

\begin{tabular}{|c|c|c|c|c|}
\hline \multirow[t]{2}{*}{$\begin{array}{l}\text { Antisecretory } \\
\text { drug }\end{array}$} & \multicolumn{2}{|c|}{$\begin{array}{l}\text { At admission } \\
(n=466)\end{array}$} & \multicolumn{2}{|c|}{$\begin{array}{l}\text { At discharge } \\
(n=647)\end{array}$} \\
\hline & $\begin{array}{l}\text { Number } \\
\text { of patients }\end{array}$ & $\%(95 \% \mathrm{CI})$ & $\begin{array}{l}\text { Number } \\
\text { of patients }\end{array}$ & $\%(95 \% \mathrm{CI})$ \\
\hline Lansoprazole & 177 & $38.0(33.7-42.5)$ & 238 & $36.8(33.2-40.6)$ \\
\hline Omeprazole & 138 & $29.6(25.6-33.9)$ & 197 & $30.4(27.0-34.1)$ \\
\hline Esomeprazole & 58 & $12.4(9.8-15.8)$ & 68 & $10.5(8.4-13.1)$ \\
\hline Rabeprazole & 43 & $9.2(6.9-12.2)$ & 88 & $13.6(11.2-16.5)$ \\
\hline Pantoprazole & 38 & $8.2(6.0-11.0)$ & 44 & $6.8(5.1-9.0)$ \\
\hline Ranitidine & 10 & $2.1(1.2-3.9)$ & 9 & $1.4(0.7-2.6)$ \\
\hline Alginic acid & 7 & $1.5(0.7-3.1)$ & 9 & $1.4(0.7-2.6)$ \\
\hline Sucralfate & 5 & $1.1(0.5-2.5)$ & 10 & $1.5(0.8-2.8)$ \\
\hline Misoprostol & 0 & 0 & 1 & $0.2(0-0.9)$ \\
\hline
\end{tabular}

(45.5\% and 54.0\%), followed by low doses of ASA and corticosteroids. Drugs for peptic ulcer or GERD in patients with inappropriate prescriptions were taken for a median of 436 days, before the admission. Comparing the characteristics of patients inappropriately receiving a drug for peptic ulcer or GERD with those appropriately not treated, the mean number of drugs was related to greater use of drugs for peptic ulcer or GERD in univariate analysis and also after adjustment for age, sex and number of diagnoses at either admission (OR 95\%CI $=1.26$ (1.18-1.34), $p=.0001)$ and discharge (OR 95\%CI = $1.11(1.05-1.18)$, $p=0.0003$ ). The mean number of diagnoses was only weakly associated with use of these drugs, and in multivariate analyses the results did not reach statistical significance (Table 4 ).

\section{Discussion}

This analyses shows mainly the high prevalence of inappropriate prescription of drugs for peptic ulcer or GERD, at hospital admission and discharge. Hospitalization is associated with rise in the rate of use of these drugs: at admission $40 \%$ of patients were taking one of these drugs, but $56 \%$ at discharge. Although these medications should be prescribed in accordance with evidence-based guidelines in order to keep down unnecessary costs and prevent adverse drug reactions, which are a particular concern in the elderly, among patients prescribed drugs for peptic ulcer or GERD, 66\% at admission and $64 \%$ at discharge did not have any appropriate indication. Though the prevalence of inappropriate use of drugs for peptic ulcer or GERD was not different at admission and discharge, it is important to underline that at discharge more patients were receiving these drugs inappropriately (304 at admission and 415 at discharge). Moreover, 23\% of patients who were appropriately not receiving these drugs at admission, were nevertheless prescribed these at discharge even without a specific indication. Furthermore prevalence of patients inappropriately not treated at admission or discharge were similar and we don't know if they were not receiving the treatment due to drug intolerance or if they were inappropriately not treated. These findings are comparable to studies conducted in other countries to evaluate the licensed or unlicensed prescription of PPI. In Greece, PPI were inappropriately prescribed to $81 \%$ of patients in a department of internal medicine [9], in UK PPI were prescribed for unlicensed indications in $67 \%$ of patients [40], and in Ireland this rate was nearly $63 \%$ [41]. In another Italian study, assessing the appropriateness of acid-suppressive therapy in a cohort of hospitalized patients and its fallout on prescriptions in general practice, anti-secretory drugs, especially PPI, were not indicated in $41.5 \%$ of patients admitted to a department of internal medicine, acceptable in $6.5 \%$ and indicated in $50.1 \%$; the main reason for inappropriate use was prophylaxis in lowrisk patients (64.8\%) [42]. In Australia, according to two studies, PPIs were appropriately prescribed only in $37.1 \%$ or $31 \%$ of cases $[5,43]$. Similarly in Spain, the prescription of PPIs was reported to be appropriate in $36.4 \%$ or $28 \%$ of patients [44,45].

Compared to other study, the main strength of our findings is that inappropriate use of these drugs is significantly related to the mean number of concomitant drug used, independently by the prescription of gastro toxic drug combinations. However a large number of coadministered drugs should not necessarily indicated the need for gastroprotective agents; closer evaluation of the underlying clinical conditions and prescribing patterns more closely linked to evidencebased guidelines and national recommendations are therefore essential for a rational, cost-effective approach. For patients in the hospital physicians should consider the possibility of withdrawing drugs for peptic ulcer or GERD if there is no pathological condition warranting their use, and in patients not taking gastro-toxic drug combinations. Patients should be given specific recommendations about how long to continue taking the drugs in order to avoid unnecessary, undefined prolongation of treatment. In our study, with a median time of 18 months of drug usage by patients with an 
Table 3

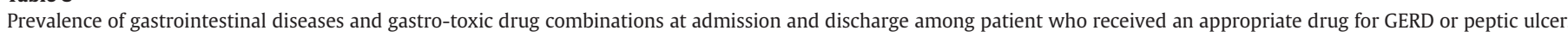

\begin{tabular}{|c|c|c|c|c|}
\hline \multirow[t]{2}{*}{ Diagnoses } & \multicolumn{2}{|l|}{$\begin{array}{l}\text { At admission } \\
(n=175)\end{array}$} & \multicolumn{2}{|l|}{$\begin{array}{l}\text { At discharge } \\
(n=238)\end{array}$} \\
\hline & Number of patients & $\%(95 \% \mathrm{CI})$ & Number of patients & $\%(95 \% \mathrm{CI})$ \\
\hline Gastrojejunal ulcer & 107 & $61.1(53.8-68.1)$ & 137 & $57.6(51.2-63.7)$ \\
\hline Gastro-toxic drug combinations & 33 & $18.6(13.8-25.3)$ & 63 & $26.5(21.3-32.4)$ \\
\hline Esophageal disease & 25 & $14.3(9.9-20.2)$ & 36 & $15.1(11.1-20.2)$ \\
\hline Gastrointestinal haemorrhage & 18 & $10.3(6.6-15.7)$ & 7 & $2.9(1.4-5.9)$ \\
\hline Gastritis and duodenitis & 5 & $2.9(1.2-6.5)$ & 4 & $1.7(0.7-4.2)$ \\
\hline Gastric ulcer & 5 & $2.9(1.2-6.5)$ & 7 & $2.9(1.4-5.9)$ \\
\hline Duodenal ulcer & 3 & $1.7(0.6-4.9)$ & 7 & $2.9(1.4-5.9)$ \\
\hline Peptic ulcer, site unspecified & 2 & $1.1(0.3-4.1)$ & 1 & $0.4(0.1-2.3)$ \\
\hline Disorders of stomach function & 1 & $0.6(0.1-3.2)$ & 4 & $1.7(0.7-4.2)$ \\
\hline Helicobacter pylori infection & 1 & $0.6(0.1-3.2)$ & 0 & 0 \\
\hline \multicolumn{5}{|l|}{ Prevalence of gastro-toxic drug combinations } \\
\hline & \multicolumn{2}{|l|}{$\begin{array}{l}\text { Admission } \\
(n=33)\end{array}$} & \multicolumn{2}{|l|}{$\begin{array}{l}\text { Discharge } \\
(n=63)\end{array}$} \\
\hline & Number of patients & $\%(95 \% \mathrm{CI})$ & Number of patients & $\%(95 \% \mathrm{CI})$ \\
\hline ASA with other antithrombotic drugs & 15 & $45.5(29.8-62.0)$ & 34 & $54.0(41.8-65.7)$ \\
\hline ASA with corticosteroids & 13 & $39.4(24.7-56.3)$ & 24 & $38.1(27.1-50.4)$ \\
\hline NSAIDs with corticosteroids & 4 & $12.1(4.8-27.3)$ & 6 & $9.5(4.4-19.3)$ \\
\hline NSAIDs with antithrombotic other than ASA & 1 & $3.0(0.5-15.3)$ & 3 & $4.8(1.6-13.1)$ \\
\hline NSAIDs with ASA & 1 & $3.0(0.5-15.3)$ & 1 & $1.6(0.2-8.5)$ \\
\hline
\end{tabular}

inappropriate prescription, it is probable that for many patients who had had diseases requiring drugs for peptic ulcer or GERD prescriptions were simply repeated although the disease was no longer present. For hospital in-patients the caregiver plays an essential role for rational and appropriate use of these drugs, discouraging prescription in patients with no symptoms or evidence-based indications. Physicians should recall the authorized indications and recommendations for licensed use of these drugs. They should constantly reassess drug therapy, considering suspending drugs in patients with no specific diseases, symptoms or gastro-toxic drug combinations. We also noted an unjustified increase in the use of gastroprotectors in hospital, which could raise the risk of drug adverse reactions and the cost for the NHS. Although lansoprazole and omeprazole, the main PPI prescribed, are available as generic drugs in Italy and are the cheapest PPI on the market, using these drugs for unlicensed or inappropriate indications is an unjustified cost. We also found that elderly patients taking multiple drugs seemed to be more likely to be inappropriately treated with a drug for peptic ulcer or GERD. The need for a large number of drugs without specific gastrotoxic combinations is not an evidence-based indication, and does not justify the use of a gastroprotective agent. The length of hospital stay was also not associated to a higher probability of receiving these drugs, in both, the univariate and multivariate model.

Patients included in the study are a representative, unselected sample of elderly in-patients in medicine wards in Italy and our analysis reflects the prescribing habits for the drugs considered. The major limit of the study is that information about drug prescriptions at admission were obtained directly from patients or relatives, so real drug use and duration of the therapy may be under-estimated compared to information at discharge, which was collected directly by the persons monitoring this study. This difference in the accuracy of data collection may have contributed to the difference in drug consumption between admission and discharge. Another limit is that we have no follow-up after discharge, whereas it would be useful to evaluate whether or not

Table 4

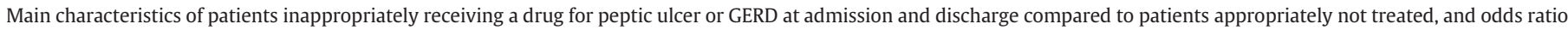
(OR) for inappropriate prescription.

\begin{tabular}{|c|c|c|c|c|}
\hline \multirow[b]{2}{*}{ Prescription of $\mathrm{A}^{02 \mathrm{~B}^{\mathrm{a}}}$} & \multicolumn{2}{|l|}{$\begin{array}{l}\text { At admission } \\
(n=994)\end{array}$} & \multicolumn{2}{|l|}{$\begin{array}{l}\text { At discharge } \\
(n=923)\end{array}$} \\
\hline & $\begin{array}{l}\text { Inappropriately treated } \\
\text { with } A 02 B\end{array}$ & $\begin{array}{l}\text { Appropriately not treated } \\
\text { with A02B }\end{array}$ & $\begin{array}{l}\text { Inappropriately treated } \\
\text { with A02B }\end{array}$ & $\begin{array}{l}\text { Appropriately not treated } \\
\text { with } \mathrm{A} 02 \mathrm{~B}\end{array}$ \\
\hline Total & 291 & 630 & 415 & 469 \\
\hline Age, yrs $($ mean $\pm S D)$ & $78.9 \pm 7.9$ & $79.2 \pm 7.4$ & $79.4 \pm 7.8$ & $79.4 \pm 7.4$ \\
\hline Women (\%) & 54.3 & 52.9 & 55.5 & 55.7 \\
\hline Number of different drugs (mean $\pm \mathrm{SD}^{\mathrm{b}}$ ) & $5.4 \pm 2.7$ & $3.9 \pm 2.4$ & $5.7 \pm 2.8$ & $4.9 \pm 2.4$ \\
\hline \multirow[t]{2}{*}{ Number of different diagnoses (mean \pm SD) } & $4.3 \pm 2.3$ & $3.8 \pm 2.2$ & $5.9 \pm 2.4$ & $5.4 \pm 2.4$ \\
\hline & OR $(95 \% \mathrm{CI})$ & $p$ & OR $(95 \% \mathrm{CI})$ & $p$ \\
\hline \multicolumn{5}{|l|}{ Univariate analyses } \\
\hline Number of drugs & $1.26(1.19-1.33)$ & $<.0001$ & $1.13(1.07-1.19)$ & $<.0001$ \\
\hline Number of diagnoses & $1.11(1.04-1.18)$ & 0.001 & $1.09(1.03-1.15)$ & 0.003 \\
\hline \multicolumn{5}{|l|}{ Multivariate analyses ${ }^{\mathrm{c}}$} \\
\hline Number of drugs & $1.26(1.18-1.34)$ & $<.0001$ & $1.11(1.05-1.18)$ & 0.0003 \\
\hline Number of diagnoses & $0.99(0.93-1.07)$ & 0.84 & $1.04(0.97-1.10)$ & 0.28 \\
\hline
\end{tabular}

${ }^{a}$ Drugs for peptic ulcer or gastro-esophageal reflux disease.

b Excluding the drugs for peptic ulcer or GERD.

c Results were corrected for age, sex, number of drugs and number of diagnoses. 
overuse of drugs for peptic ulcer or GERD in the elderly in hospital is then related to over-prescription in general practice.

\section{Learning points}

- In many cases patients taking PPI had no appropriate indication and physicians fail to provide specific instructions about how long to continue treatment.

- Inappropriate use of PPI is significantly related to the mean number of concomitant drug used, independently by the prescription of gastro toxic drug combinations.

- Closer evaluation of the underlying clinical conditions and prescribing patterns more closely linked to evidence-based guidelines and national recommendations are essential for a rational, cost-effective approach.

\section{Acknowledgements}

The authors thank Mrs Judith Baggott (Mario Negri Institute, Milan) for the english revision of the manuscript and for editorial assistance.

The authors declare that they have no conflict of interest.

Sponsor's Role: none.

\section{Appendix A. Collaborators and participating units}

The following hospital and investigators have contributed to this study: Pier Mannuccio Mannucci, Alberto Tedeschi, Raffaella Rossio (Medicina Interna 2, Fondazione IRCCS Ospedale Maggiore, Milano); Guido Moreo, Barbara Ferrari (Medicina Interna 3, Fondazione IRCCS Ospedale Maggiore, Milano); Cesare Masala, Antonio Mammarella, Valeria Raparelli (Medicina Interna, Università La Sapienza, Roma); Carulli Nicola, Stefania Rondinella, Iolanda Giannico (Medicina Metabolica, Università di Modena e Reggio Emilia); Leonardo Rasciti, Silvia Gualandi (Medicina Interna, Policlinico S. Orsola Malpighi, Bologna); Valter Monzani, Valeria Savojardo (Medicina d'Urgenza, IRCCS Fondazione Ospedale Maggiore, Milano); Cappellini Maria Domenica, Giovanna Fabio, Flavio Cantoni (Medicina Interna 1A, Fondazione IRCCS Ospedale Maggiore, Milano); Dallegri Franco, Luciano Ottonello, Alessandra Quercioli, Alessandra Barreca (Medicina Interna 1, Università di Genova); Riccardo Utili, Emanuele Durante-Mangoni, Daniela Pinto (Medicina Interna, Seconda Università di Napoli); Roberto Manfredini, Elena Incasa, Emanuela Rizzioli (Medicina Interna, Azienda USL, Ferrara); Massimo Vanoli, Gianluca Casella (Medicina Interna, Ospedale di Lecco, Merate); Giuseppe Musca, Olga Cuccurullo (Medicina Interna, P.O. Cetraro, ASP Cosenza); Laura Gasbarrone, Giuseppe Famularo, Maria Rosaria Sajeva (Medicina Interna, Ospedale San Camillo Forlanini, Roma); Antonio Picardi, Dritan Hila (Medicina Clinica-Epatologia, Università Campus Bio-Medico, Roma); Renzo Rozzini, Alessandro Giordano (Fondazione Poliambulanza, Brescia); Andrea Sacco, Antonio Bonelli, Gaetano Dentamaro (Medicina, Ospedale Madonna delle Grazie, Matera); Francesco Salerno, Valentina Monti, Massimo Cazzaniga (Medicina Interna, IRCCS Policlinico San Donato, Università di Milano); Ingrid Nielsen, Piergiorgio Gaudenzi, Lisa Giusto (Medicina ad Alta Rotazione, Azienda Ospedaliera Universitaria, Ferrara); Enrico Agabiti Rosei, Damiano Rizzoni, Luana Castoldi (Clinica Medica, Università di Brescia); Daniela Mari, Giuliana Micale (Medicina Generale ad indirizzo Geriatrico, IRCCS Istituto Auxologico Italiano, Milano); Emanuele Altomare, Gaetano Serviddio, Santina Salvatore (Medicina Interna, Università di Foggia); Carlo Longhini, Cristian Molino (Clinica Medica, Azienda Mista Ospedaliera Universitaria Sant'Anna, Ferrara); Giuseppe Delitalia, Silvia Deidda, Luciana Maria Cuccuru (Clinica Medica, Azienda Mista Ospedaliera Universitaria, Sassari); Giampiero Benetti, Michela Quagliolo, Giuseppe Riccardo Centenaro (Medicina 1, Ospedale di Melegnano, Vizzolo Predabissi, Milano); Alberto Auteri,
Anna Laura Pasqui, Luca Puccetti (Medicina Interna, Azienda Ospedaliera Universitaria Le Scotte, Siena); Carlo Balduini, Giampiera Bertolino, Piergiorgio Cavallo (Dipartimento di Medicina Interna, Fondazione IRCCS Policlinico San Matteo, Università degli Studi di Pavia); Ronchi Esio, Daniele Bertolini, Nicola Lucio Liberato (Medicina Interna, Ospedale Carlo Mira, Casorate Primo, Pavia); Antonio Perciccante, Alessia Coralli (Medicina, Ospedale San Giovanni-Decollato-Andisilla, Civita Castellana); Luigi Anastasio, Leonardo Bertucci (Medicina Generale, Ospedale Civile Serra San Bruno); Giancarlo Agnelli, Ana Macura, Alfonso Iorio, aura Marcucci (Medicina Interna e Cardiovascolare, Ospedale Santa Maria della Misericordia, Università di Perugia); Cosimo Morabito, Roberto Fava (Medicina, Ospedale Scillesi d'America, Scilla); Giuseppe Licata, Antonino Tuttolomondo, Riccardo Di Sciacca (Medicina Interna e Cardioangiologia, Università degli Studi di Palermo); Luisa Macchini, Anna Realdi (Clinica Medica 4, Università di Padova); Luigi Cricco, Alessandra Fiorentini, Cristina Tofi (Geriatria, Ospedale di Montefiascone); Carlo Cagnoni, Antonio Manucra (UO Medicina e Primo Soccorso, Ospedale di Bobbio, Azienda USL di Piacenza); Giuseppe Romanelli, Alessandra Marengoni, Bonometti Francesca (UO Geriatria, Spedali Civili di Brescia); Michele Cortellaro, Maria Rachele Meroni, Magenta Marina (Medicina 3, Ospedale Luigi Sacco, Università di Milano); Carlo Vergani, and Dionigi Paolo Rossi (Geriatria, Fondazione IRCCS Ospedale Maggiore e Università di Milano).

Clincal data monitoring and revision: Valentina Spirito, Damia Noce, Jacopo Bonazzi, Rossana Lombardo, Luigi de Vittorio (Istituto di Ricerche Farmacologiche "Mario Negri”, Milano.

\section{References}

[1] Forgacs I, Loganayagam A. Overprescribing proton pump inhibitors. BMJ 2008;336:2-3.

[2] AIFA. L'uso dei farmaci in Italia. Rapporto nazionale anno 2008. http://www. agenziafarmaco.it/allegati/rapporto_osmed_2008.pdf (accessed on october 2009).

[3] Walker NM, McDonald. An evaluation of the use of proton pump inhibitors. Pharm World Sci 2001;23:116-7.

[4] Batuwitage BT, Kingham JGC, Morgan NE, Bartlett RL. Inappropriate prescribing of proton pump inhibitors in primary care. Postgrad Med J 2007;83:66-8.

[5] Naunton M, Peterson GM, Bleasel MD. Overuse of proton pump inhibitors. J Clin Pharm Ther 2000;25:333-40.

[6] Lanza FL, Chan FK, Quigley EM. Practice Parameters Commitee of the American College of Gastroenterology. Guidelines for prevention of NSAID-related ulcer complications. Am J Gastroenterol 2009;104:728-38.

[7] AIFA. Le Note AIFA per l'uso appropriato dei farmaci. http://www.agenziafarmaco. it./wscs_render_attachment_by_id/111.90291.1168607405163575e.pdf? id $=111.88204 .11685966288822008$

[8] George CJ, Korc B, Ross JS. Appropriate proton pump inhibitor use among older adults: a retrospective chart review. Am J Geriatr Pharmacother 2008;6:249-54.

[9] Ntaios G, Chatzinikolaou A, Kaiafa G. Evaluation of use of proton pump inhibitors in Greece. Eur J Intern Med 2009;20:171-3.

[10] Ryder SD, O'Reilly S, Miller RJ, Ross J, Jacyna MR, Levi AJ. Long term acid suppressing treatment in general practice. BMJ 1994;308:827-30.

[11] Hollingworth S, Duncan EL, Martin JH. Marked increase in proton pump inhibitors use in Australia. Pharmacoepidemiol Drug Saf Oct 2010;19(10):1019-24.

[12] Howden CW, henning JM, Huang B. Management of heartburn in a large, randomized, community based study: comparison of fuor therapeutic strategies. Am J Gastroenterol 2001;96:1704-10.

[13] Caro JJ, Salas M, Ward A. Healing and relapse rates in gastroesophageal reflux disease treated with the newer proton pump inhibitors lansoprazole, rabeprazole and pantoprazole compared with omeprazole, ranitidine and placebo: evidence from randomize clinical trials. Clin Ther 2001;23:998-1017.

[14] Wu CY, Chan FK, Wu MS, Kuo KN, Wang CB, Tsao CR, et al. Histamine2-receptor antagonists are an alternative to proton pump inhibitor in patients receiving clopidogrel. Gastroenterology 2010;139(4):1165-71.

[15] Woodhouse KW, O'Mahony MS. Frailty and aging. Age Aging 1997;26:245-6.

[16] Gurwitz JH, Rochon P, for the Food and Drug Administration (US). Improving the quality of medication use in elderly patients: a not-so-simple prescription. Arch Intern Med 2002;162:1670-2.

[17] Simonson W, Feinberg JL. Medication-related problems in the elderly: defining the issues and identifying solutions. Drugs Aging 2005:22:559-69.

[18] Laheij RJ, Sturkenboom MC, Hassing RJ. Risk of community-acquired pneumonia and use of gastric acidsuppressive drugs. JAMA 2004;292:1955-60.

[19] Gulmez SE, Holm A, Frederiksen H. Use of proton pump inhibitors and the risk of community-acquired pneumonia. A population-based case-control study. Arch Intern Med 2007;167:950-5.

[20] Sarkar M, Hennessy S, Yang YX. Proton-pump inhibitor use and the risk for community-acquired pneumonia. Ann Intern Med 2008;149:391-8. 
[21] Herzig SJ, Howell MD, Ngo LH. Acid-suppressive medication use and the risk for hospital-acquired pneumonia. JAMA 2009;301(20):2120-8.

[22] Dial S, Delaney JA, Barkun AN, Suissa S. Use of gastric acid-suppressive agents and the risk of community acquired Clostridium difficile-associated disease. JAMA 2005;294:2989-95.

[23] Choudhry MN, Soran H, Ziglam HM. Overuse and inappropriate prescribing of proton pump inhibitors in patients with Clostridium difficile-associated disease. OIM 2008;101:445-8.

[24] Linsky A, Gupta K, Lawler EV, Fonda JR, Hermos JA. Proton pump inhibitors and risk for recurrent Clostridium difficile infection. Arch Intern Med 2010;170(9): 772-8.

[25] Bhatt DL. COGENT: A prospective, randomized, placebo-controlled trial of omeprazole in patients receiving aspirin and clopidogrel. Presented at: Transcatheter Cardiovascular Therapeutics; September 24, 2009; San Francisco, Calif.

[26] Ho PM, Maddox TM, Wang L. Risk of adverse outcomes associated with concomitant use of clopidogrel and proton pump inhibitors following acute coronary syndrome. JAMA 2009;301(9):937-44.

[27] Juurlink DN, Gomes T, Ko DT. A population-based study of the drug interaction between proton pump inhibitors and clopidogrel. CMAJ 2009;180(7).

[28] Juurlink DN. Proton pump inhibitors and clopidogrel putting the interaction in perspective. Circulation 2009;120:2310-2.

[29] Rassen JA, Choudhry NK, Avorn J. Cardiovascular outcomes and mortality in patients using clopidogrel with proton pump inhibitors after percutaneous coronary intervention or acute coronary syndrome. Circulation 2009;120:2322-9.

[30] Stockl KM, Le L, Zakharyan A, Harada AS, Solow BK, Addiego JE, Ramsey S. Risk of rehospitalization for patients using clopidogrel with a proton pump inhibitor. Arch Intern Med 2010;170(8):704-10.

[31] Yang YX, Lewis JD, Epstein S, Metz DC. Long-term proton pump inhibitor therapy and risk of hip fracture. JAMA 2006;296:2947-53.

[32] Targownik LE, Lix LM, Metge CJ. Use of proton pump inhibitors and risk of osteoporosis-related fractures. CMAJ 2008;179:319-26.
[33] Gray SL, LaCroix AZ, Larson J, Robbins J, Cauley JA, Manson JE, et al. Proton pump inhibitor use, hip fracture, and change in bone mineral density in postmenopausal women: results from the Women's Health Initiative. Arch Intern Med 2010;170 (9):765-71.

[34] Fernández-Fernández FJ, Sesma P. Gastric cancer. Lancet 2009;374(9701):1594 7.

[35] Bell JS, Strandberg TE, Teramura-Gronblad M, Laurila JV, Tilvis RS, Pitkälä KH. Use of proton pump inhibitors and mortality among institutionalized older people. Arch Intern Med Sep 27 2010;170(17):1604-5.

[36] World Health Organization. International Classification of Diseases, Injuries, and Causes of Death. . Ninth Revision (ICD-9).Geneva: World Health Organization; 1987.

[37] World Health Organization. Guidelines for ATC Classification. Sweden, WHO Collaborating Centre for Drug Statistics Methodology, Norway and Nordic Councils on Medicines, 1990.

[38] Graham DY, Agrawal NM, Campbell DR, Haber MM, Collis C, Lukasik NL, et al. NSAIDAssociated Gastric Ulcer Prevention Study Group. Ulcer prevention in long-term users of Nonsteroidal Antinflammatory Drugs. Arch Intern Med 2002;162:169-75.

[39] Derry S, Loke YK. Risk of gastrointestinal hemorrhage with long term use of aspirin: meta-analysis. BMJ 2000;321:1183-7.

[40] Walker NM, McDonald J. An evaluation of the use of proton pump inhibitors. Pharm World Sci 2001;23(3):116-7.

[41] Sebastian SS, Kernan N, Qasim A. Appropriateness of gastric antisecretory therapy in hospital practice. Ir J Med Sci 2003;172(3):115-7.

[42] Parente F, Cucino C, Gallus S. Hospital use of acid-suppressive medications and its fall-out on prescribing in general practice: a 1-month survey. Aliment Pharmacol Ther 2003;17:1503-6.

[43] Pillans PI, Kubler PA, Radford JM, Overland V. Concordance between use of proton pump inhibitors and prescribing guidelines. Med J Aust 2000;172:16-8.

[44] De Burgas Lunar C, Novo del Castillo S, Llorente Díaz E. Study of prescriptionindication of proton pump inhibitors. Rev Clín Esp Jun 2006;206(6):266-70.

[45] Asensio AN, Barrientos RR, Castro PZ. Use of acid-suppressive medications in hospitalized patients. Ann Med Intern Nov 2002;19(11):557-60. 